\title{
El análisis estructural de los sectores de actividad: crítica del modelo de las cinco fuerzas del M.E. Porter
}

\author{
The structural analysis of Business, criticism of the five forces model \\ of M.E. Porter
}

Gustavo E. Mata Fernández-Balbuena

CEPADE. Industriales Escuela de Negocios. Universidad Politécnica de Madrid

Carlos Rodríguez Monroy

Departamento de Organización, Escuela Técnica Superior de Ingenieros Industriales. Universidad Politécnica de Madrid gmatafb@gamail.com cmonroy@etsii,upm.es

Fecha de recepción: 29-10-09

Fecha de aceptación: 03-03-10

Resumen: En el artículo se hace una revisión crítica del modelo que el profesor Porter propone para realizar el análisis estructural de los sectores de actividad: Las cinco fuerzas que condicionan la competencia en un sector.

Palabras clave: Cinco fuerzas de Porter, posibilidad de nuevos entrantes, barreras de entrada, rivalidad competitiva, existencia de sustitutivos, poder negociador de proveedores, poder negociador de clientes, competencia, rentabilidad estructural, análisis estructural de los sectores de actividad.

Abstract: The article presents a critical review of the Porter's five forces model for the industry analysis.

Key words: Porter's five forces, threat of new entrants, barriers of new entry, competitive rivalry within an industry, threat of substitutes, bargaining power of suppliers, bargaining power of clients, competition, structural profitability, structural analysis of the industries.

\section{Introducción}

\section{El modelo de las cinco fuerzas de Porter: las fuerzas que determinan la competencia en un sector}

El modelo (Porter, 1980) es masivamente utilizado -probablemente, es el más conocido y divulgado de cuantos modelos se aplican en el análisis estratégico- pues representa una interesante síntesis descriptiva de todos los aspectos que influyen en la intensidad de la competencia en un sector de actividad. Para Porter, la competencia en un sector no sólo está determinada por el grado de rivalidad entre los competidores en el sector, también la posible entrada de nuevos competidores, la existencia de productos sustitutivos, el poder negociador de los clientes y el poder negociador de los proveedores, contribuyen como fuerzas determinantes a configurar la estructura competitiva del sector.

\section{Algunas observaciones críticas al modelo de las cinco fuerzas de M.E. Porter}

\section{I. Una advertencia preliminar obvia: el modelo es para el análisis estructural de los sectores de actividad}

En primer lugar, se debe señalar que el modelo de las cinco fuerzas es un modelo de análisis genérico y que, por tanto, se refiere a las características del sector de actividad, más allá del papel de cada una de las empresas en el mismo. Pese a ello, no es insólito encontrar el análisis de las cinco fuerzas - «las fuerzas que determinan la competencia en un sector», según el propio M.E. Porter- aplicado directamente a una empresa, calificando el poder negociador de clientes y proveedores, la amenaza de sustitutivos o la amenaza de nuevos entrantes, no genéricamente, en el sector, sino específicamente, para una empre- 
Figura I.

Las cinco fuerzas de Porter (adaptado de Porter, Michael E. 1982. ESTRATEGIA COMPETITIVA. CEC SA de CV.)

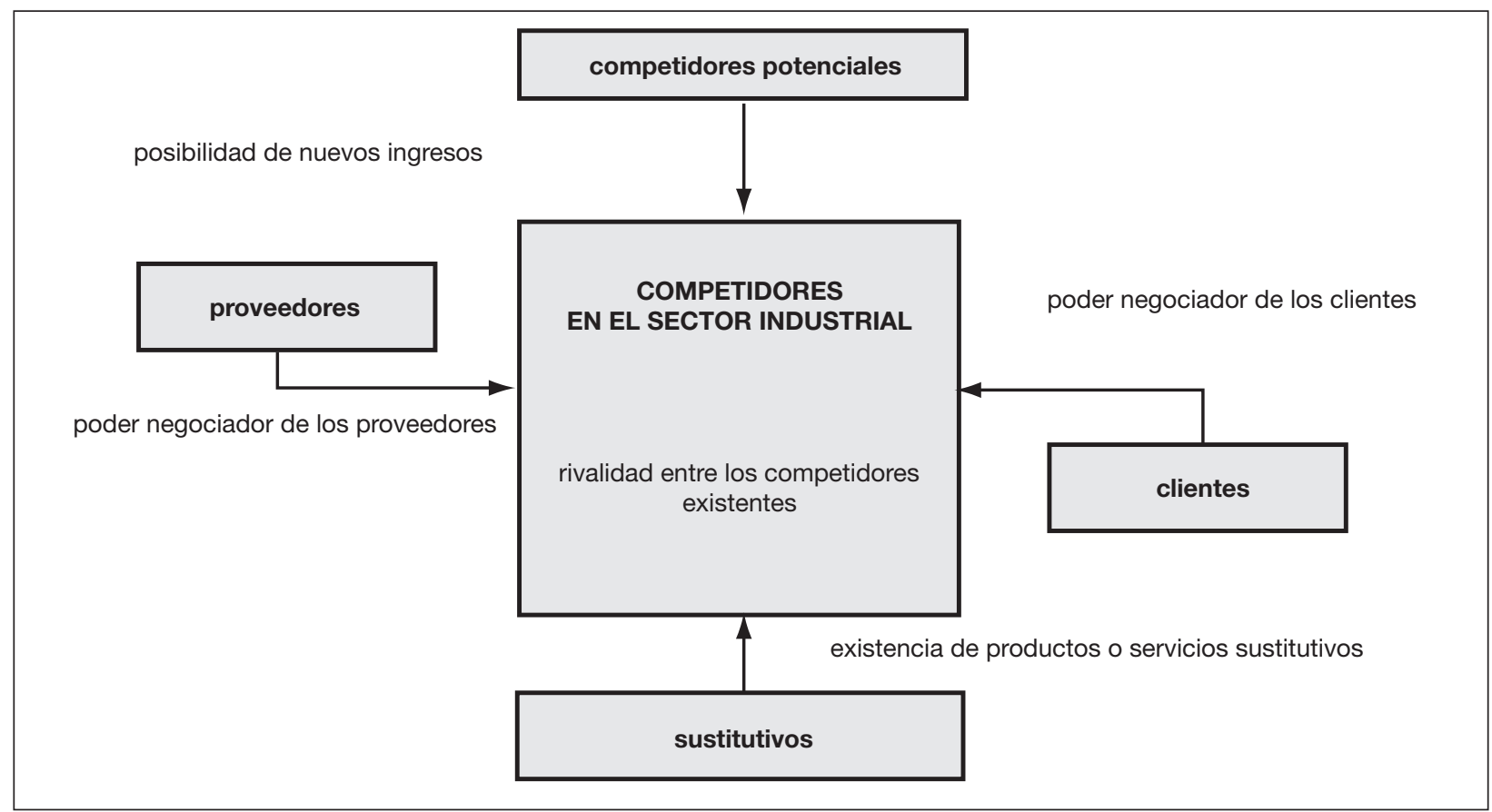

sa en concreto. Éste es un error de planteamiento muy frecuente.

\subsection{Competencia y rentabilidad}

Para comprender el modelo es necesario, en primer lugar, entender bien a qué nos referimos cuando hablamos de competencia en un sector. Cuando se dice que un sector es más o menos competido nos estamos refiriendo a la posibilidad mayor o menor de obtener beneficios en el mismo. Los beneficios, en el sentido económico del término, son excedentes que genera la actividad después de la retribución de los factores de producción a su coste, incluida, también, la retribución del capital al interés competitivo. Un sector con mucha competencia es aquel que no permite que los concurrentes obtengan excedentes y un sector con poca competencia es aquel en que los beneficios son posibles. Cuando el profesor Porter se refiere a la competencia se está refiriendo a lo opuesto a la posibilidad de obtener rendimientos de la inversión.

Recordemos el concepto microeconómico de la competencia perfecta: un sector donde hubiera un gran número de compradores y de vendedores, que no tuviera barreras para acceder al sector ni barreras para abandonarlo, en el que los productos no fueran, en absoluto, diferenciados y en donde la infor- mación circulara libremente sería un sector en competencia perfecta. La ausencia de barreras de entrada y de salida sería equivalente a la perfecta movilidad de todos los factores de producción -es decir, a la ausencia de costes fijos- y la perfecta accesibilidad a la información querría decir que todos los concurrentes tendrían la misma curva de coste -la idónea-. El hecho de que hubiera un gran número de empresas del lado de la oferta significaría que la escala mínima eficiente admisible de producción sería muy pequeña en relación al tamaño del mercado. Y el hecho adicional de que la demanda estuviera también atomizada conduciría a que todas las empresas asumirían el precio fijado por el mercado, pues ninguna podría influir en él. Se podría decir que un sector en competencia perfecta sería aquel en el que se cumplieran cuatro condiciones: los productos serían indiferenciados, habría perfecta movilidad de los factores de producción, habría información perfecta para productores y para consumidores $y$, tanto productores como consumidores serían precio-aceptantes, asumirían el precio fijado por el mercado, pues no podría influir, de modo apreciable, en él. En un sector en competencia perfecta, si el precio fuera superior al coste medio mínimo de las empresas habría beneficios y si los hubiera entrarían más competidores bajando éstos; con lo que el ajuste de la oferta a la demanda se haría, finalmente, vía número de empresas. Todas las empresas tendrían siempre su producción ajustada al punto de coste medio míni- 
Figura 2.

Curvas de indiferencia.

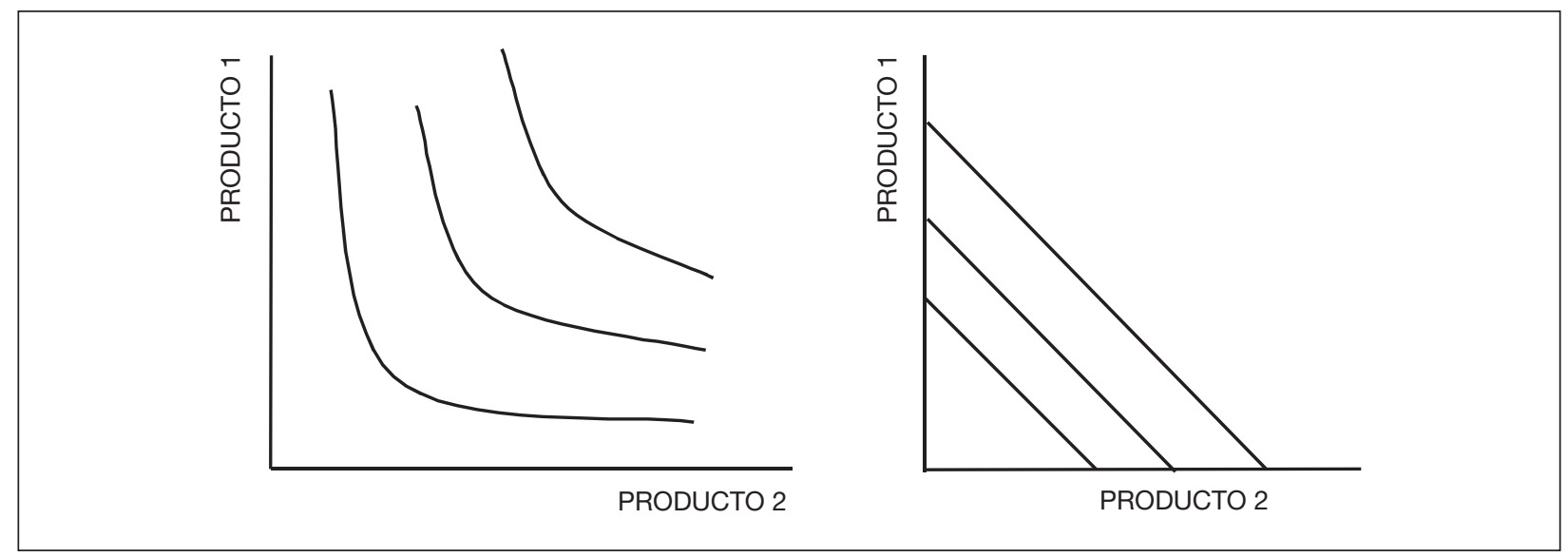

mo a largo plazo, que incluiría como coste la retribución del factor capital -el tipo de interés a largopero ningún beneficio real. $\bigcirc$ sea todos los factores estarían retribuidos a su coste pero no habría ningún beneficio adicional; aunque tampoco habría riesgo alguno. El precio sería el coste medio mínimo y la curva de oferta global de las empresas sería una recta horizontal, la correspondiente a ese coste medio mínimo. Dicho de otro modo, más sencillo, en un sector sin barreras de entrada, si los beneficios fueran mayores que el interés del dinero a largo plazo los capitales acudirían y se instalarían, lo que incrementaría la competencia y haría disminuir los beneficios; si no hubiera barreras de salida, cuando los beneficios fueran más bajos que el interés a largo plazo muchos abandonarían el sector, la competencia disminuiría y los beneficios para los que se hubieran quedado crecerían. Por tanto la máxima competencia -la competencia perfecta- equivaldría al beneficio nulo -es decir al beneficio que se tendría dejando el dinero a largo plazo en el banco, no más-. Cualquier condición restrictiva de esa competencia está en el origen de la posibilidad de obtener más rentabilidad.

En parte importante, en el análisis estructural de Porter se trata de ver como la ausencia de las condiciones que darían lugar a la competencia perfecta condiciona una competencia imperfecta, es decir una menor competencia, lo que equivale a que, de darse esta ausencia de condiciones, se abra la posibilidad de beneficios en el sector.

En el análisis estructural, sería más claro referirse a lo que condiciona la rentabilidad genérica alcanzable en el sector que referirse a la competencia en el mismo. Cuando se habla de sectores con mayor o menor competencia se generan muchas confusiones mientras que refiriéndose a la rentabilidad genérica alcanzable jamás se genera confusión alguna.

\subsection{Competidores y sustitutivos. La definición formal de los límites del sector de actividad}

Producto es cualquier bien material, servicio o idea susceptible de satisfacer una necesidad. (American Marketing Association). Lo que hace que los entes -bienes, servicios o ideas- pasen a ser productos es su utilidad, su capacidad de satisfacer necesidades; el valor de los productos se deriva de su utilidad. Es importante que recordemos que los servicios son productos; aunque usualmente digamos productos y servicios, deberíamos decir productos: bienes y servicios. Los productos diferentes que se dirigen a satisfacer la misma necesidad son los que denominamos productos sustitutivos. La forma inequívoca de determinar si dos productos son sustitutivos entre sí es conocer si los cambios de precio en uno afectan a la demanda en el mercado del otro y al revés. Si hubiera elasticidad cruzada habría relación de sustitución y los productos serían sustitutivos; si no la hubiera, no. La elasticidad cruzada entre un producto y sus distintos sustitutivos puede ser mayor o menor; en la misma medida que haya elasticidad cruzada hay efecto de sustitución; así: un producto es igual a otro -es decir, es un sustitutivo perfecto del mismo- cuando satisface la necesidad de forma perfectamente equivalente y al mismo precio. Para que dos productos fueran sustitutivos, debería haber una relación de sustitución entre ambos; esta relación de sustitución daría lugar a una curva de indiferencia correspondiente a las combinaciones de ambos productos que fueran equivalentes en la satisfacción de la necesidad. Cualquier combinación de los dos pro- 
ductos sustitutivos entre sí que diera lugar a una misma satisfacción de la necesidad serían los puntos de una misma curva de indiferencia. Si las curvas de indiferencia fueran rectas de pendiente - I, querría decir que los productos serían sustitutivos perfectos, absolutamente intercambiables, no sólo serían sustitutivos, sino que tendrían el mismo precio; si no hubiera relación de sustitución entre ellos, no serían sustitutivos.

Un sector de actividad es un espacio virtual en el que concurren oferentes y demandantes de un producto. Para definir un sector de actividad habría que identificar cuál es el producto, cuál es la necesidad objetiva cubierta por el producto, quiénes son los demandantes, quiénes son los oferentes -los que producen el producto- y cuáles son los productos sustitutivos y su grado de proximidad al producto del sector como tales sustitutivos. En la práctica, hay algo natural en la selección de los límites un sector. Las restricciones geográficas condicionan el mercado al alcance de los grupos de competidores y consumidores. También las restricciones políticas o culturales influyen en la determinación de los límites de un sector de actividad. Pero también hay un criterio formal a la hora de definir un sector de actividad que hace difícil precisar los conceptos.

Para poder definir un sector de actividad, en sentido estricto, tendría que haber un producto absolutamente indiferenciable y ser perfectamente equivalente el acceso de cada competidor a cada oferente. En un sector en el que haya diferenciación, cada segmento del mercado percibe de forma diferenciada a los distintos productos, de forma que cada modalidad específica de producto es la preferida para cada segmento diferenciado, que considera a los demás productos sustitutivos próximos pero no perfectos del que prefieren. Un sector en el que los productos sean diferenciados implica que haya segmentos de mercado diferenciados en él. En cada sector el criterio o los criterios relevantes para identificar los segmentos serán unos u otros, pero, en cualquier caso, la característica común de un mercado así, con diferenciación de los productos, será que cada segmento de mercado será susceptible de ser atendido, de forma ventajosa, con una propuesta específica de producto adaptado a su necesidad específica.

Si se tomásen en consideración los productos sustitutivos próximos a la hora definir un sector, como se podrían emplear criterios más o menos restrictivos de proximidad, o más o menos laxos, es evidente que se podrían definir sectores más homogéneos o más heterogéneos. Cuanto más amplio fuera el criterio a la hora de considerar a los sustitutivos no perfectos del producto dentro del sector y éste agrupara a segmentos diferenciados de clientes, éste sería más heterogéneo. Entonces, ¿cómo se puede definir un sector con productos diferenciados? La solución suele estar en considerar que los sustitutivos más próximos y homogéneos son un grupo estratégico -que es lo que se considera el sector de actividad-y que los grupos de sustitutivos más alejados son considerados productos sustitutivos. Esa es la propuesta de Porter. Pero con una tal imprecisión formal en la definición del sector de actividad, no es improbable que surjan interpretaciones diversas acerca de qué es producto y qué son sustitutivos en los sectores de actividad. Sin embargo es clave definir bien este punto si se quiere que el análisis estructural del sector sea adecuado. Por ejemplo, si hablásemos del sector de los fabricantes de mantequilla, está claro que la margarina sería un sustitutivo, pero si hablásemos del sector de las cadenas de tiendas de moda -tipo ZARA, MANGO, H\&M- ¿qué sería EL CORTE INGLÉS: competidor o sustitutivo? Lo oportuno es considerar que es un sustitutivo; y es sustitutivo porque compite, y pese a competir no es competidor porque lo hace de una forma suficientemente diferente como para que se considere sustitutivo. En estos casos los competidores son el grupo de sustitutivos más cercanos unos a otros, cuasi perfectos y los sustitutivos los sustitutivos menos perfectos.

Para cada grupo de sustitutivos habría que definir el impacto que tiene sobre la rentabilidad esperable en el sector, por su influencia sobre los precios en el sector, o porque desvíen demanda del sector al sector sustitutivo.

\section{4. ¿Cuál es la diferencia entre rivalidad competitiva e intensidad de la competencia?}

La disposición de cuatro de las fuerzas alrededor de otra, como influyendo en ella, en la llamada rivalidad competitiva, invita a la reflexión. ¿Son cinco las fuerzas o son sólo cuatro? ¿Por qué el profesor Porter sitúa la rivalidad competitiva -una de las cinco fuerzas según él- en el centro y a las otras cuatro rodeando a ésta? ¿Es que la intensidad de la competencia -el resultado de las cinco fuerzas- es algo diferente de la llamada rivalidad competitiva -la fuerza central en su modelo?

Evidentemente, las restricciones al acceso de nuevos competidores al sector de actividad, las denominadas barreras de entrada, pueden propiciar que en el sector haya condiciones de competencia restringida 
y son una de las fuerzas que configuran la competencia en el sector; también la inexistencia de productos sustitutivos podría actuar de la misma manera; estas dos fuerzas - posibilidad de nuevos entrantes y existencia de sustitutivos- tendrían como consecuencia una mayor o menor intensidad de la rivalidad competitiva, como el propio Porter reconoce al hablar de ella. El poder negociador de los proveedores y el poder negociador de los clientes, que en la negociación sobre los precios podrían transferir parte de los beneficios «propios del sector» al suyo, serían las otras dos «fuerzas» que terminarían de definir la competencia en el sector según él, aunque está más claro cómo estas dos fuerzas influyen en la rentabilidad alcanzable, más que cómo lo hacen sobre la competencia. Decir, entonces, que la propia intensidad de la rivalidad competitiva en el sector-que para Porter es una de las cinco «fuerzas»- influye en la competencia del sector, es, cuando menos, poco preciso ¿Qué es la rivalidad competitiva en el sector?; ¿es la intensidad de la competencia, o sea el resultado de la influencia de las otras cuatro «fuerzas citadas», o es «otra fuerza» que influye en sí misma? Desde una perspectiva didáctica se entiende al profesor: él trata de ilustrar que al analizar los condicionantes estructurales de la competencia en un sector, además de fijarse en la rivalidad competitiva, hay que fijarse en lo que condiciona ésta; sobre todo en las barreras a la entrada de competidores nuevos y en el impacto de los sustitutivos. No es riguroso hacerlo así, pero es práctico. Luego, para completar el análisis, añade el rol del poder negociador de proveedores y clientes, que más que en la competencia, en sentido estricto, o en la llamada por él rivalidad competitiva, influyen en la detracción de los beneficios potenciales a que éstos condicionantes -barreras de entrada al sector y sustitutivos- diera lugar, desde el sector a los sectores proveedores o a los sectores clientes, e impactan así en la rentabilidad alcanzable.

\subsection{Posibilidad de nuevos entrantes, barreras de entrada y rentabilidad}

Es fácil estar de acuerdo con Porter en que el análisis de las barreras de entrada al sector y su relación con la posibilidad de tener beneficios en él es fundamental, pero no es sencillo llevarlo a término; es bastante más complejo de lo que parece a primera vista. Lo que está claro es que si no hay barreras al acceso de nuevos competidores no habrá beneficios en el sector, pero no se puede decir, como si se tratara de un dogma, que a mayores barreras de en- trada habrá mayores beneficios (Mata, 2008). No es cierto; para empezar habría que precisar mejor la definición de barrera que para Porter es «todo aquello que impide o dificulta el acceso de los competidores potenciales al sector». Es erróneo, como sostiene Porter, que la existencia de barreras a la entrada se puede resumir, finalmente, en la posibilidad para los instalados de practicar precios disuasorios para el ingreso de competidores potenciales; a este respecto se debe señalar que, en primer lugar, hay veces en las que no es posible el acceso para nadie más, independientemente del precio que haya en el mercado; en segundo lugar, si un nuevo entrante supiera que la fijación de precios bajos sólo se hace para disuadir su entrada, sabría también, que de entrar, todos se verían en la necesidad de subir el precio para poder tener beneficios, con lo que la señal sería falsa y, por tanto, inválida. Relacionar biunívocamente el tamaño de las barreras de entrada con los beneficios esperables en el sector es, cuando menos, poco riguroso. Habría que definir con precisión, para empezar, cómo se mide el tamaño de las barreras y no es sencillo (Bain, 1956). Podemos, en principio, diferenciar entre barreras absolutas, las que impiden el acceso -como la exclusividad o el domino total sobre un factor de producción indispensable o sobre el único canal de distribución posible, que pueden dar lugar, o no, a que haya beneficios en la actividady barreras relativas, que si bien disuaden, no llegan a impedir el acceso de competidores potenciales; pero no se puede establecer, en modo alguno, una correlación simple entre el tamaño de las barreras de acceso a un sector, tal y como las define Porter, y la cuantía de los beneficios obtenibles en él. Entre otras cosas porque barreras eficaces, absolutas, pueden dar lugar a rentabilidades discretas sobre los activos, como ocurre en entornos concentrados, en los que la competencia se basa en bajar el precio y aumentar la cuota de mercado, y a altas rentabilidades cuando se trata de entornos de alta especialización, en donde cada competidor se dirige a un segmento específico para el que es el exclusivo, si bien, en este caso, el tamaño de los segmentos de mercado al alcance de cada exclusivista suele ser más pequeño, lo que hace al sector menos atractivo, pero no menos rentable.

\subsection{Barreras de salida y riesgo}

Las barreras de salida tampoco tienen una correlación directa con el riesgo en el sector. Las barreras de salida tienen, cuando menos, dos efectos: el que presentan éstas para los instalados, que, en efecto, 
de haberlas, podría incrementarse el riesgo para ellos, y que de no haberlas se reduciría; y el efecto para los competidores potenciales, que, de no haberlas, sabedores de la facilidad con la que podrían deshacer su operación de entrada, no tendrían grandes reparos en entrar, por lo que, pese a la existencia de barreras de entrada, entrarían, aumentando así el riesgo para los instalados, convirtiendo el sector en un mercado impugnable (Baumol, 1982). Considerando pues el segundo efecto, la no existencia de barreras a la salida convertiría al sector en competitivo pese a la existencia de barreras de entrada y, por lo tanto, su no existencia aumentaría el riesgo para los instalados en lugar de disminuirlo como sostiene el profesor Porter.

En cualquier caso, un aspecto tan fundamental en la actividad empresarial como el riesgo no se puede despachar relacionándolo simplemente con el análisis de las barreras de salida. El análisis del riesgo es algo mucho más complejo que la visión que Porter hace de él, relacionándolo sólo con las barreras de salida; el riesgo está relacionado con la mayor o menor incertidumbre con la que se pueden prever las variables que afectan al sector y se concreta en la denominada prima de riesgo con la que se resume lo que el riesgo supone para la rentabilidad esperable en un determinado sector.

\subsection{El ciclo de vida y la rivalidad}

Sostiene el profesor Porter que la rivalidad competitiva es mayor cuando el crecimiento de la demanda se atenúa. Cuesta poco admitir esta aseveración, pues intuitivamente parece correcta. Si hubiera crecimiento en la demanda parece que los concurrentes estarían menos apremiados que si no la hubiera. ¿Pero es realmente así?

En entornos concentrados, donde operan las economías de escala y la curva de experiencia como barreras, la pelea por la cuota de mercado se desarrolla principalmente mientras el mercado crece. En esa fase de crecimiento acelerado cada competidor trata de apropiarse de la mayor cuota posible a costa de bajar los precios para conseguir crecer más que el mercado e ir expulsando de esta manera a los que no resistan esa competencia por tener costes más altos. Recuérdese el célebre modelo crecimiento participación de The Boston Consulting Group (Henderson, 1970). El líder del mercado, mientras éste crece aceleradamente -la estrella-, debe repercutir sus bajadas en coste -las que le va proporcionando su ventaja en experiencia acumulada- en el precio, para así ir creciendo más que el mercado y ganado más y más cuota; sólo cuando el mercado deja de crecer tanto, cuando ya quedan muy pocos competidores -que es cuando el producto estrella se torna vaca: vaca de caja- se piensa en recuperar la inversión manteniendo los precios; los demás -los perros- ya no tienen capacidad para seguir luchando frente al líder y se resignan a su papel de seguidores; ¡no van a atacar al líder con sus armas!; el resultado es que en estos entornos cuando el crecimiento se atempera disminuye la intensidad de la rivalidad. Es decir ocurre, en este tipo de entornos concentrados, que no son pocos, exactamente lo contrario de lo que afirma Porter sobre el efecto del crecimiento en la rivalidad competitiva, que intuitivamente todos admitíamos. Mientras el mercado crece y crece cada vez más, en entornos de volumen, la rivalidad competitiva es insoportable, tanto que muchos deben abandonar el sector; sólo cuando el crecimiento se atempera la rivalidad es menor entre los supervivientes.

\subsection{La influencia del poder negociador de los proveedores en la rentabilidad del sector}

Porter soslaya en su análisis algo trascendental: que el poder de negociación de proveedores y clientes puede estar del lado de unos, de otros, o de ambos. Si Porter reconoce que el poder negociador de los clientes influye en el sector, debe reconocer, y no lo hace, que el poder negociador del sector frente a sus proveedores también influye. De la misma manera, si el profesor admite que el poder de los clientes influye en el sector, debe admitir que el poder del sector frente a sus proveedores también influye. Es decir se debería analizar, además del poder negociador de los proveedores o de los clientes sobre el sector, el poder negociador del sector sobre los proveedores y sobre los clientes. No es quién tiene más poder-el sector proveedor o el sector cliente- lo que importa, sino determinar si tienen o no poder tanto unos como otros.

Además el poder de negociación es una cosa y la posibilidad de que ese poder pueda tener mayor o menor repercusión en la rentabilidad del sector es otra. Porter confunde claramente ambas cosas. Lo que interesa determinar en el análisis estructural de un sector, no es el poder de negociación de unos u otros, lo que importa es la influencia que el poder de negociación de los diferentes sectores proveedores sobre el sector y la influencia que el poder de negociación del sector sobre los diferentes sectores 
proveedores tengan sobre la rentabilidad genérica alcanzable en el sector. Cuando un sector proveedor tenga poder de negociación sobre el precio del factor suministrado, dependerá de la elasticidad de la demanda del factor y de la influencia del coste del factor suministrado en el coste total del producto, el que ese poder tenga una mayor o menor repercusión en la rentabilidad estructural. El proveedor persigue la optimización de sus beneficios: si la demanda es muy inelástica el proveedor subirá mucho los precios para garantizarse la optimización de los mismos pues la cantidad demandada se verá poco afectada por las subidas, mientras que si la demanda es muy elástica lo que le interesará será aumentar la cantidad demandada moviendo poco los precios a la baja. Pero el impacto sobre la rentabilidad dependerá además, de lo que el factor suponga en los costes de producción. Para que el poder de negociación de los proveedores de un factor determinado sobre el sector o del sector sobre los sectores proveedores tenga impacto sobre la rentabilidad del sector es necesario que haya poder de negociación, que la elasticidad de la demanda del factor sea escasa y, sobre todo, que el factor tenga un impacto grande en los costes. Aún cuando haya poder de negociación, si la demanda es muy elástica y el factor supone muy poco en los costes del sector, esa influencia será irrelevante, por más que el poder de negociación sea muy alto.

\subsection{La influencia del poder negociador de los clientes en la rentabilidad del sector}

Evidentemente, lo mismo que ocurre cuando se analiza el poder de negociación de los proveedores, ocurre cuando se analiza el poder de negociación de los clientes; cuando el cliente tenga algún poder de negociación intentará traer los beneficios del sector y obligará a éste a bajar el precio, hasta llegar incluso al coste medio, si puede, dejando a éste sin beneficios. Pero, también en este caso, habría que analizar, además del poder de negociación de los clientes frente a las empresas del sector, el poder de las empresas del sector frente a los clientes; también aquí, son aspectos diferentes.

\subsection{El poder del sector para fijar el precio a los clientes}

Además, aún más trascendental que lo mencionado resulta lo siguiente: el que las empresas tengan poder de negociación del precio frente a los clientes o no lo tengan, está en la esencia de que haya posibilidad de beneficios en el sector o no. Ese es el obje- to primero del análisis estructural. En efecto, si una empresa tiene poder para negociar el precio frente a sus clientes es porque tiene cierto poder de fijación del precio en su mercado o sus mercados. Por tanto, no tiene demasiado sentido el análisis del poder de negociación sobre los clientes de forma independiente, como si de otra «fuerza» se tratase, cuando es la clave que determina la posibilidad de que haya beneficios o no.

\section{EI análisis estructural de los sectores, basado en el modelo de las cinco fuerzas de Porter, adaptado según nuestra visión}

\subsection{Enfoque general}

El objetivo es delimitar los aspectos que condicionan estructuralmente la rentabilidad alcanzable por las empresas que operen viablemente en el sector.

Inicialmente se delimitará formalmente qué es el sector, quiénes son los considerados competidores y a qué se va a considerar sustitutivos, para que el análisis pueda resultar consistente.

Se trata, en primer lugar, como hace Porter, de determinar las barreras para el acceso de los nuevos competidores. Pero se deben distinguir las barreras según su origen, para describir mejor sus efectos sobre la rentabilidad estructural alcanzable en el sector. A continuación se analizará el impacto de los sustitutivos sobre los precios y sobre la demanda a disposición del sector. Ahora ya se puede determinar qué capacidad tiene el sector para fijar los precios a sus clientes -que viene condicionada por las barreras y por los sustitutivos-. Luego se debe analizar si algún tipo de clientes tiene poder para negociar el precio de compra y se tratará de determinar el impacto que sobre la rentabilidad alcanzable supone ese poder, que dependerá no sólo del poder negociador de esos clientes, también de la elasticidad de la demanda del producto ofertado al precio y de lo que las ventas a esos clientes supongan en el total de las ventas del sector. Sólo quedaría volver la vista hacia los diferentes proveedores y comprobar si éstos están en condiciones de forzar los precios de los suministros, y estimar el impacto que ese poder tendría sobre los beneficios del sector, según sea de inelástica la demanda del bien o servicio comprado y según sea de grande el porcentaje que esa compra signifique sobre las ventas del sector; aunque puede que ocurra que el sector tenga la capacidad de negociar los precios de los suministros y 
que ese poder tenga influencia en la rentabilidad del sector, que será tanto mayor cuanto mayor sea el monto de las compras de ese bien o servicio y cuanto menor sea la elasticidad de la oferta del bien al precio.

\subsection{EL EFECTO ESTRUCTURAL DE LAS BARRERAS}

\subsubsection{Barreras de acceso y potencial estructural} de fijación de los precios por parte del sector

Las barreras de acceso a un sector de actividad se deben a dos grandes grupos de condiciones: si el mercado global está al alcance de todos los competidores y no hay diferenciación posible entre ellos, éstas sólo pueden deberse a la necesidad de tener un coste lo suficientemente bajo para ser viable -una condición que sí tendrían los instalados y que no sería posible o fácil de conseguir para los otros-; si en el sector hay segmentos diferenciados susceptibles de ser atendidos con una oferta específica que sea preferible a las demás ofertas, éstas deberían deberse a la necesidad de ser percibido como muy diferen- ciado o exclusivo por uno de los segmentos del mercado, para poder operar en él, siempre que esa condición no estuviera al alcance de los otros o, cuando menos, no fuera fácil alcanzarla.

\subsubsection{Entornos genéricos según el tipo de barreras (Mata 2007, 2008): (origen causal) y el tamaño de las mismas}

Clasificación del tamaño de las barreras: I, el tamaño de la barrera es irrelevante; 2 , el tamaño de la barrera es poco relevante, ineficaz; 3 , el tamaño de la barrera ya es relevante, empieza a condicionar la competencia restringiéndola; 4, el tamaño de la barrera es muy relevante, condiciona la entrada de nuevos competidores haciéndola muy difícil; y 5, el tamaño de la entrada de nuevos competidores resulta imposible, la competencia está limitada a los que ya están.

En un entorno tipo $A$, el mercado es segmentado y cada segmento requiere de unas características tan singulares para ser viable en él que lo hacen estanco, es decir, independiente del resto de los segmentos.

Figura 3.

Entornos genéricos (elaboración propia)

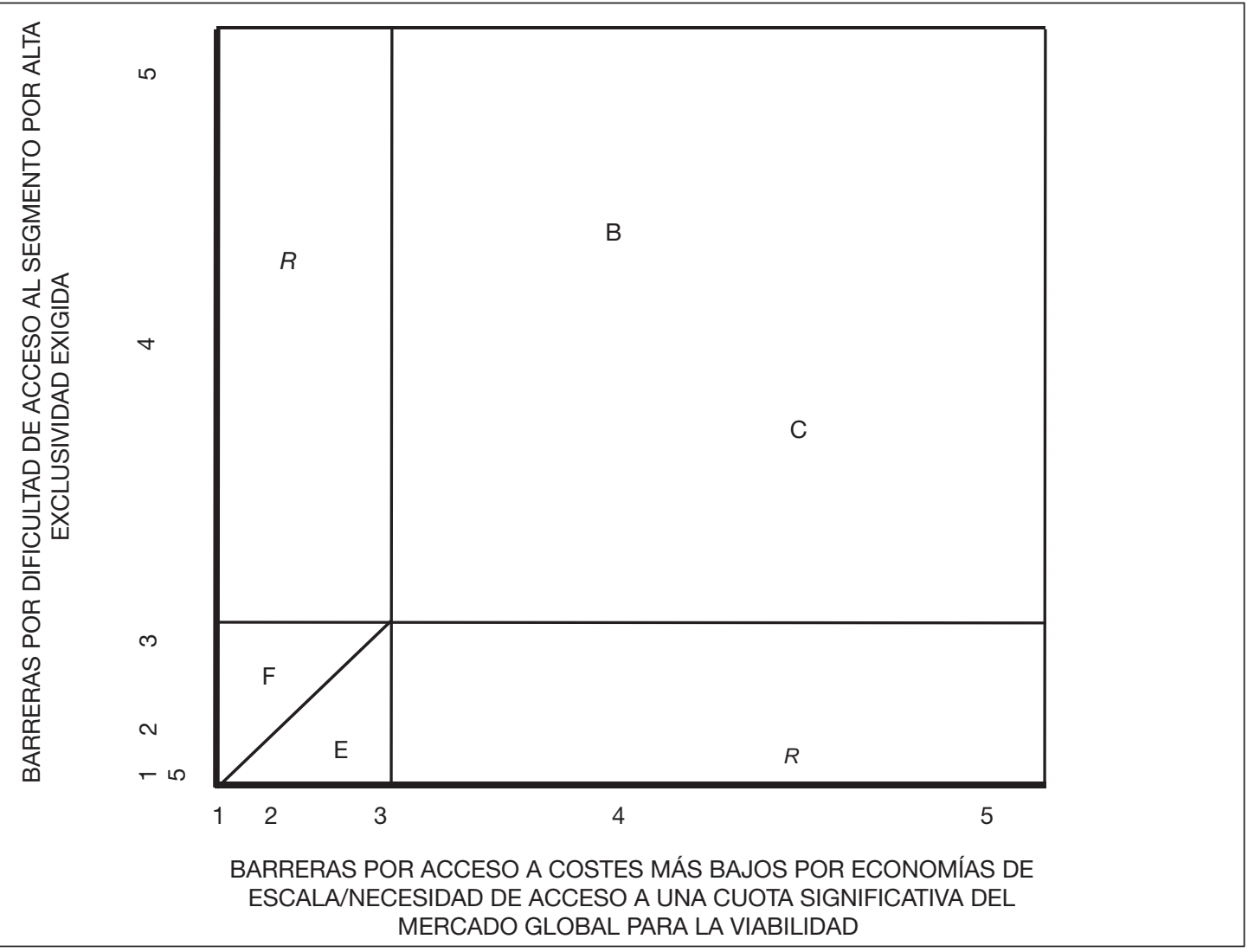


Figura 4.

Correlación entre rentabilidad y cuota en cada entorno genérico (elaboración propia)
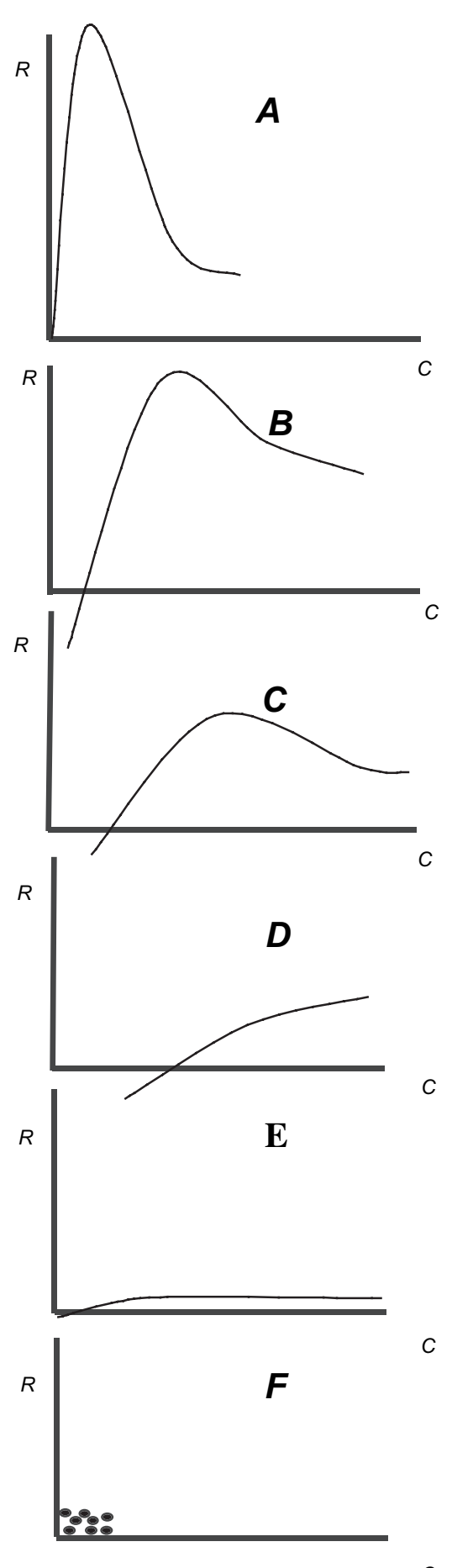

Aquí, la rentabilidad sería máxima para una mínima cuota del mercado global, la del segmento en el que cada uno resulta exclusivo; en cuanto se trata de entrar en otro segmento la exclusividad en el segmento de origen se resiente y la rentabilidad cae. Los productos -bienes o servicios- apellidados de lujo son así. En un entorno de alta especialización, no tiene sentido luchar por cuota del mercado conjunto. Sabemos que en este tipo de entornos la máxima rentabilidad se obtiene para una cuota limitada al segmento estanco de interés. En estos entornos la rentabilidad puede ser muy alta pero la segmentación impone que el tamaño de las empresas no sea, ni mucho menos, tan grande como si se dirigieran al mercado global.

En un entorno tipo B hay segmentos de mercado estancos, aunque pocos y grandes, y en cada segmento pueden caber unos pocos competidores que son percibidos como exclusivos, pero, además, hay economías de escala, cuyo efecto como barrera de entrada se ve ahora reforzado por actuar en un segmento en lugar de en todo el mercado. Las cadenas de tiendas especializadas en moda, serían sectores así. También serían así las cadenas de tiendas especializadas, los «category killers», como tiendas de muebles, de material deportivo, «garden centers», etc. Cuando, en este entorno, el negocio que crece a base de sucursales que se integran puede alcanzar ventajas competitivas derivadas de la agregación, aparecen barreras por tamaño y la posibilidad de obtener beneficios.

En un entorno tipo C pesan más las economías de escala que la especialización, pero ambas están presentes. Cada competidor compite en un segmento grande que puede compartir con otros y las economías de escala son evidentes. Las compañías aéreas Ilamadas de bajo coste que compiten cada una en su nicho geográfico en torno a un aeropuerto base pueden ser un buen ejemplo.

En un entorno tipo D, asimilable al modelo teórico del oligopolio natural, las economías de escala conducen a una estructura con pocos competidores; y la rentabilidad es mayor cuanto mayor cuota se tiene. Ejemplos: los servicios de telefonía para el mercado doméstico y PYMES, las cadenas de hipermercados, la banca de particulares, etc. Todos tienen todo el mercado a su alcance, y compiten de la única forma posible: luchan con las mismas armas por alcanzar la máxima cuota de mercado; esa lucha se establece en torno al precio bajo que marca quien accede al coste más bajo que, de esa manera, pone a los otros en desventaja y se apropia del crecimiento del mercado mientras este crece, ganando más y más cuota. En este tipo de segmentos la rentabilidad no es nunca muy alta, porque la competencia se basa en el coste, aunque el tamaño alcanzable es enorme.

En un entorno tipo E, asimilable a un entorno perfectamente competitivo, la rentabilidad sería muy baja, la 
Figura 5.

Rentabilidad alcanzable en cada tipo de entorno (Curvas de iso-rentabilidad) (elaboración propia)

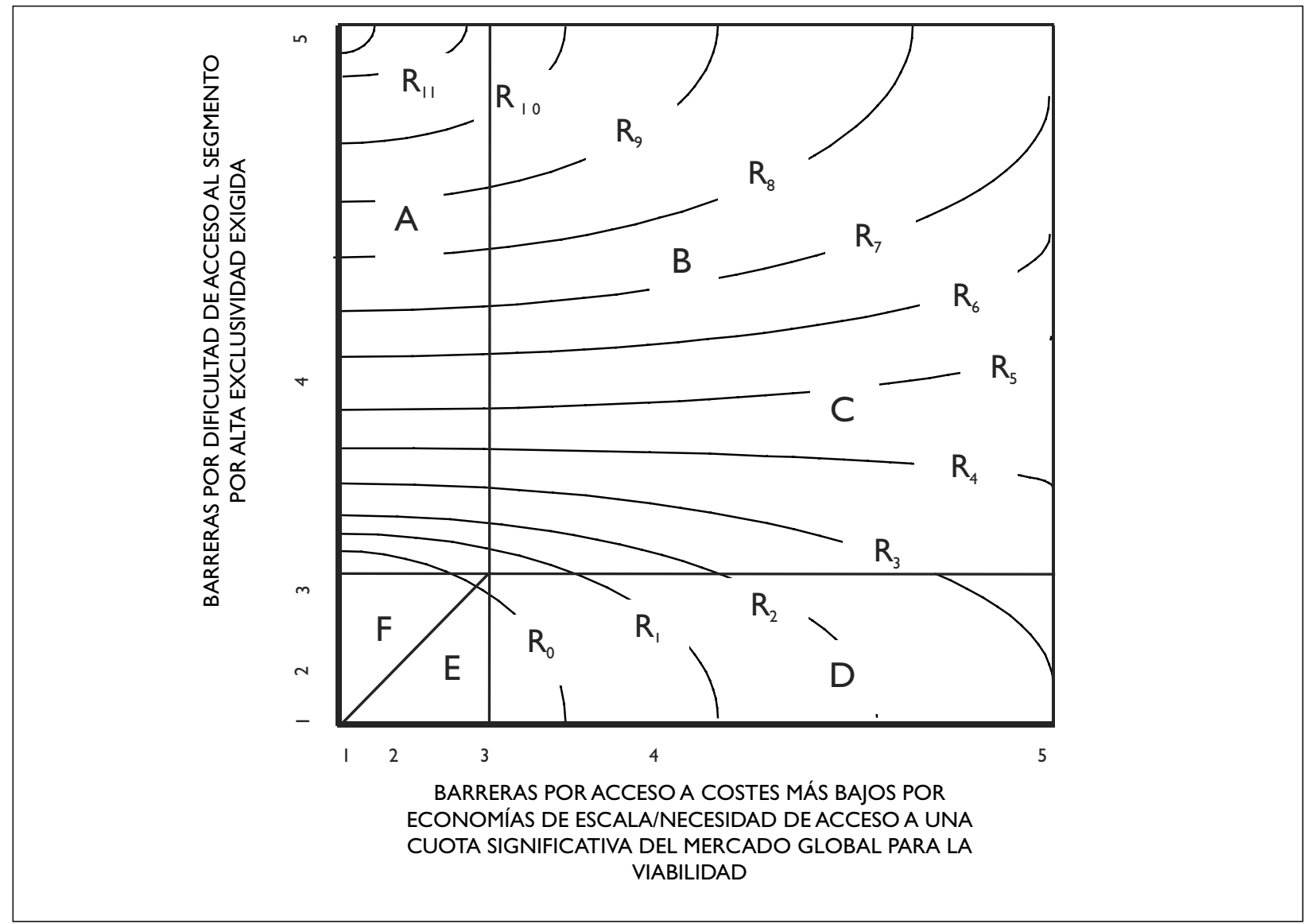

correspondiente al tipo de interés a largo plazo más la prima de riesgo que el sector pudiera tener por incertidumbre; y ésta no dependería de la cuota de mercado que se alcanzara, sería la misma para todos a partir de un tamaño muy pequeño en relación al tamaño del mercado. En estos sectores la estructura de la oferta sectorial puede estar atomizada y haber sólo empresas pequeñas, aunque también puede ocurrir que haya empresas grandes aunque el tamaño no supone mayor rentabilidad; lo probable es que haya cualquier mezcla de empresas grandes y pequeñas atacando el mercado global. Un mercado real parecido sería el de cualquier «commodity» agrícola -trigo, maíz, soja, girasol, etc.-. Puede haber explotaciones enormes, grandes o más pequeñas, todas con la misma rentabilidad, la competitiva, pues a partir de un tamaño pequeño en relación al tamaño del mercado ya no hay economías de escala. En un entorno tipo A el crecimiento por penetración del mercado es posible, pues el mercado está al alcance de todos, aunque, como decíamos, disponer de mayor tamaño no incrementa la rentabilidad. Es claro que en este tipo de entornos crecer supone tener un negocio más grande, pero no más rentable.
En un entorno tipo F, asimilable a la competencia monopolística, la rentabilidad sería también muy pequeña, como en el caso anterior, y tampoco dependería de la cuota de mercado alcanzada, que, además, en este caso, sería siempre muy escasa para cada competidor, pues la segmentación del mercado no permitiría a cada uno dirigirse a todo el mercado sino sólo a una pequeña parte de él. Eso es lo que condiciona que en este caso la estructura de la oferta sectorial sólo pueda ser fragmentada: con muchos competidores muy pequeños. Un mercado real parecido sería el de la confección no especializada, o servicios como el pequeño comercio, peluquerías, tintorerías, etc. En un entorno tipo $\mathrm{F}$ la penetración de todo el mercado es imposible porque cada competidor tiene a su alcance sólo una parte de él; la única forma de penetrarlo sería por adición de diferentes operadores en cada segmento; es decir, un negocio para ser grande, en un sector fragmentado así, tendría que disponer de muchas sucursales, cada una de las cuales actuaría en su nicho, aunque ese hecho tampoco le pondría en ventaja respecto de la rentabilidad alcanzable por el conjunto, que seguiría siendo la rentabilidad competitiva. 


\subsection{El efecto de los denominados sustituivos}

Los sustitutivos lo son porque compiten, y no son competidores directos porque compiten de otra manera. Definido el sector con criterio restrictivo como recomienda Porter y como se decía más arriba, considerando competidores directos al grupo estratégico de los competidores más próximos y sustitutivos a aquellos que aún compitiendo lo hacen de forma suficientemente diferente como para no poder ser considerados competencia directa, se hace especialmente importante considerar el efecto que sobre la rentabilidad alcanzable en el sector y sobre la demanda a disposición del mismo tiene cada tipo de sustitutivo. Los sustitutivos detraen demanda al sector y condicionan los precios; ihasta qué punto? eso es lo que se trata de determinar en el análisis estructural.

3.4. El poder de fijar los precios a los clientes, el poder de los clientes de negociar los precios y su impacto sobre la rentabilidad alcanzable

Una vez analizado el papel de las barreras -el más decisivo en cuanto a la rentabilidad alcanzable- y el posible efecto condicionante de los sustitutivos, ya se tienen las claves para determinar cuál es la capacidad del sector para fijar los precios, es decir lo que se podría llamar la capacidad de negociación sobre los clientes. A mayor capacidad de fijar los precios, mayor rentabilidad estructural alcanzable y menor rivalidad competitiva.

Esta capacidad de fijar precios por encima de los costes, es algo diferente del poder de negociación que puedan tener los clientes. Puede que en función de que agrupen una parte significativa de la demanda total no sean precio aceptantes, tengan poder de negociar y lo hagan. Determinemos si los sectores clientes tienen capacidad para negociar los precios y estimemos el impacto que este poder tiene sobre la rentabilidad alcanzable en el sector.

3.5. El poder de los proveedores de negociar los precios de los suministros, el poder del sector de negociar esos precios y su impacto sobre la rentabilidad

Finalmente pudiera ocurrir que alguno de los sectores proveedores tuviera capacidad de negociación sobre los precios de los suministros al sector. Es decir, puede que algunos de los sectores proveedores estén en condiciones de detraer parte de los beneficios del sector porque tengan poder de negociación sobre los suministros de un factor determinado que suponga una parte importante de los costes y que tenga una demanda relativamente inelástica. Baste considerar que cualquier sector proveedor está también sometido al impacto de las barreras de acceso al mismo y al impacto de los sustitutivos, lo que determinaría su capacidad de fijar los precios. Si la demanda de esos factores fuera poco elástica y esos suministros supusieran un monto importante en la cuenta de resultados del sector, el impacto sobre la rentabilidad de ese poder de negociación puede ser muy alto.

Aunque también puede ocurrir que el sector, porque agrupe una parte significativa de la demanda de un determinado factor, tenga poder de negociación, y que esté en condiciones de detraer beneficios de los sectores proveedores hasta incluso conseguir comprar al coste medio de producción del factor. De esa forma también puede incrementar su rentabilidad estructural a costa de la del sector proveedor.

\section{Conclusiones: resumen de factores relevantes en el entorno próximo para determinar la rentabilidad estructural de un sector de actividad}

En un análisis estructural, definido el sector de actividad con criterio restrictivo para permitir un análisis consistente, $y$ definidos los diferentes sustitutivos, se trata de determinar el entorno genérico del sector fijando: las barreras derivadas de la dificultad de alcanzar el coste requerido para la viabilidad de una empresa en el sector y las barreras derivadas de la dificultad de lograr la exclusividad requerida por el segmento de clientes para la viabilidad de una empresa en el sector.

Determinadas las barreras de acceso y estimado su efecto se puede determinar la capacidad estructural del sector para fijar precios a su conveniencia. Si el entorno es tipo $\mathrm{E}$ o $\mathrm{F}$ no hay ninguna capacidad de fijar pecios por encima de los costes medios, incluyendo en ésos la retribución de todos y cada uno de los factores a su coste. Si el entorno es tipo D la capacidad de fijar precios existe: el líder en coste -que será el de mayor tamaño, con mayor cuota de mercado global-, fijará el precio lo suficientemente bajo para preservar para él una gran cuota de mercado y expulsar del sector a la mayoría de los competidores. Si el entorno es tipo A la capacidad de fijar el 
precio, sin tomar en cuenta los costes, sólo pensando en obtener la máxima rentabilidad, restringiendo las ventas a la cuota que representa el segmento de interés en el global del agregado sectorial, será plena. Para los entornos mixtos las condiciones serán también mixtas.

Puesto que se han considerado competidores directos al grupo estratégico de los competidores más próximos y sustitutivos a aquellos que aún compitiendo lo hacen de forma suficientemente diferente como para no poder ser considerados competencia directa, es necesario considerar el efecto que sobre la rentabilidad alcanzable en el sector y sobre la demanda a disposición del mismo tiene cada tipo de sustitutivo.

Ya se tienen las claves para determinar cuál es la capacidad final del sector para fijar los precios. Y ilos sectores clientes tienen capacidad para discutir los precios que el sector les trata de imponer?: sólo lo tendrán cuándo agrupen demanda o representen una parte importante de la misma que les permita dejar de ser precio aceptantes. Es evidente que ese poder tendría impacto sobre la rentabilidad alcanzable para el sector.

Finalmente, pudiera ocurrir que alguno de los sectores proveedores tuviera capacidad de negociación sobre los precios de los suministros del sector. Si la demanda de esos factores fuera poco elástica y esos suministros supusieran un monto importante en la cuenta de gastos del sector, el impacto sobre la rentabilidad del sector de ese poder de negociación de los proveedores podría ser muy alto. Aunque también puede ocurrir que sea el sector, como cliente, por su poder de negociación frente a los proveedores, el que esté en condiciones de detraer beneficios de ellos hasta incluso conseguir comprar al coste medio de producción del factor que compre. Si ese poder afecta mucho al precio y se trata de un factor que influye mucho en los costes totales, el impacto de ese poder sobre los proveedores será alto para el sector; el sector también puede incrementar su rentabilidad estructural a costa de la del sector proveedor.

Así se completaría el análisis pues analizar ahora la rivalidad competitiva, como si de algo diferenciado se tratara, o la competencia, como si fuera algo diferente de la rentabilidad alcanzable habría dejado de tener, a nuestro juicio, sentido.

\section{Bibliografía}

BAIN, J. (1956). Barriers to New Competition, Harvard University Press, Boston, MA, USA

BAUMOL,W. (1982). «Contestable markets: An Uprising in the Theory of Industry Structure», American Economy Review, 72, Marzo

HENDERSON, BD. ( 1970). «La cartera de productos» en (1998) Stern, CW y Stalk, G (eds), Ideas sobre estrategia, Deusto, Bilbao, ESPAÑA

MATA, G. (2007). «Modalidades de crecimiento de las empresas según el entorno genérico del sector», Revista de Economía ICE, No 239, Noviembre-Diciembre

MATA, G. (2008). «Las barreras para la entrada de competidores potenciales a los sectores de actividad y su influencia en la posibilidad de obtener beneficios en los mismos», Revista de Dirección, Organización y Administración de Empresas de La Fundación General de la Universidad Politécnica de Madrid, N. ${ }^{\circ}$ 36, Octubre

MATA, G. (2008). «Un nuevo modelo de clasificación de los entornos genéricos de las actividades empresariales», Revista de Economía y Derecho de la Sociedad de Economía y Derecho UPC, Universidad Peruana de Ciencias Aplicadas, $N^{\circ} 20$. Primavera

PORTER, ME. (1980). Competitive Strategy, Free Press, New York, USA

RECKLIES, D. (200I). «Beyond Porter - A critique of the critique of Porter», Recklies Management Project GmbH, Junio

REINISCH, HA. (2003). «Since 1980. An incremental assesment of Michael Porters Aproach to Strategy», LSE/Lent Term Paper, Febrero 